\title{
In vitro Ultrasonic Potentiation of 2-Phenylethynesulfonamide/Magnetic Fluid Hyperthermia Combination Treatments for Ovarian Cancer
}

\author{
Fernando Mérida ${ }^{1}$ \\ Carlos Rinaldi ${ }^{2,3}$ \\ Eduardo J Juan (iD) \\ Madeline Torres-Lugo' \\ 'Department of Chemical Engineering, \\ University of Puerto Rico-Mayagüez, \\ Mayagüez, Puerto Rico; ${ }^{2}$ Department of \\ Chemical Engineering, University of Florida, \\ Gainesville, FL, USA; ${ }^{3}$ J. Crayton Pruitt \\ Family Department of Biomedical \\ Engineering, University of Florida, \\ Gainesville, FL, USA; ${ }^{4}$ Department of \\ Electrical and Computer Engineering, \\ University of Puerto Rico-Mayagüez, \\ Mayagüez, Puerto Rico
}

This article was published in the following Dove Press journal: International Journal of Nanomedicine
Background: Magnetic Fluid Hyperthermia (MFH) is a promising adjuvant for chemotherapy, potentiating the action of anticancer agents. However, drug delivery to cancer cells must be optimized to improve the overall therapeutic effect of drug/MFH combination treatments. Purpose: The aim of this work was to demonstrate the potentiation of 2-phenylethynesulfonamide (PES) at various combination treatments with MFH, using low-intensity ultrasound as an intracellular delivery enhancer.

Methods: The effect of ultrasound (US), MFH, and PES was first evaluated individually and then as combination treatments. Definity ${ }^{\circledR}$ microbubbles and polyethylene glycol (PEG)-coated iron oxide nanoparticles were used to induce cell sonoporation and $\mathrm{MFH}$, respectively. Assessment of cell membrane permeabilization was evaluated via fluorescence microscopy, iron uptake by cells was quantified by UV-Vis spectroscopy, and cell viability was determined using automatic cell counting.

Results: Notable reductions in cancer cell viability were observed when ultrasound was incorporated. For example, the treatment US+PES reduced cell viability by $37 \%$ compared to the non-toxic effect of the drug. Similarly, the treatment US+MFH using mild hyperthermia $\left(41^{\circ} \mathrm{C}\right)$, reduced cell viability by an additional $18 \%$ when compared to the effect of $\mathrm{MH}$ alone. Significant improvements were observed for the combination of US+PES+MFH with cell viability reduced by an additional $26 \%$ compared to the PES+MFH group. The improved cytotoxicity was attributed to enhanced drug/nanoparticle intracellular delivery, with iron uptake values nearly twice those achieved without ultrasound. Various treatment schedules were examined, and all of them showed substantial cell death, indicating that the time elapsed between sonoporation and magnetic field exposure was not significant.

Conclusion: Superior cancer cell-killing patterns took place when ultrasound was incorporated thus demonstrating the in vitro ultrasonic potentiation of PES and mild MFH. This work demonstrated that ultrasound is a promising non-invasive enhancer of PES/MFH combination treatments, aiming to establish a sono-thermo-chemotherapy in the treatment of ovarian cancer. Keywords: MFH, ultrasound, sonoporation, microbubble, PES, membrane permeabilization, enhanced cytotoxicity

\section{Introduction}

The current standard of care in the treatment of ovarian cancer faces challenges associated with chemotherapy resistance, often attributed to irregular drug distribution and poor penetration into solid tumors. ${ }^{1}$ As an experimental cancer therapy, magnetic 
fluid hyperthermia (MFH) pursues the physiological heating of a tumor $\left(41-47^{\circ} \mathrm{C}\right)$ via thermal energy released by magnetic nanoparticles under the action of an alternating magnetic field (AMF). This local, minimally invasive hyperthermia approach aims to reduce cancer cell growth while improving the effects of chemotherapy. ${ }^{2}$ Experimental evidence supports the notion that MFH potentiates cytotoxic effects of chemotherapeutic agents while sensitizing resistant cancer cells, and this often occurs at mild hyperthermia temperatures $\left(\sim 41^{\circ} \mathrm{C}\right),{ }^{3,4}$ This phenomenon is of particular interest in the field of $\mathrm{MFH}$, because reaching moderate hyperthermia temperatures $\left(\geq 43{ }^{\circ} \mathrm{C}\right)$ in tumors remains a challenge, as it requires large nanoparticle doses for effective accumulation in cancerous tissues and sufficient heat generation. ${ }^{5}$ Some studies have reported enhanced cytotoxic effects of drugs such as cisplatin and bortezomib when used in combination with MFH, inducing sensitivity in resistant cancer cells. ${ }^{6-8}$ In vivo studies have also demonstrated the thermal potentiation of drugs like cisplatin and doxorubicin via MFH, resulting in significant tumor volume reductions in mice. ${ }^{9,10}$ Recently, Court et al investigated the thermal potentiation of 2-phenylethynesulfonamide (PES), an inhibitor of the function of the heat-shock proteins (HSP70). The combined PES/MFH treatment was demonstrated to be synergistic leading to significantly higher ovarian cancer cell death when compared to MFH or PES individual treatments. In addition, significant tumor volume reductions were observed in vivo after $\mathrm{PES} / \mathrm{MFH}$ co-administration in mice bearing intraperitoneal ovarian tumors. ${ }^{11}$ Despite promising results, one of the limitations for the clinical translation of drug/MFH combination therapies is the required optimal concentrations of drugs and nanoparticles in tumor cells, which is difficult to attain in the clinical setting. In addition to poor penetration of drugs into tumors, efficient drug uptake by cancer cells is limited by the chemical composition of the drug molecule, especially for hydrophilic molecules with unpredictable active uptake pathways. ${ }^{1}$ Among the strategies to improve the delivery of drugs and nanoparticles to tumors, the use of physical methods poses a potential advance compared to conventional chemical conjugations. Low-intensity-focused ultrasound (LIFU) has been suggested for the transient, structural alteration of endothelial barriers and cell membranes, improving drug and nanoparticle distribution. ${ }^{12}$ The aim of LIFU is to facilitate the extravasation of particles and drug molecules to tumors and their subsequent internalization into tumor cells, using ultrasound waves as external stimuli. The rationale behind the ultrasound-improved cellular uptake of drugs and nanoparticles is the transient permeabilization of cell membranes caused by gas-filled microbubbles excited by ultrasound, undergoing mechanical cavitation without thermal effects. ${ }^{12}$ This phenomenon is known as sonoporation and is capable of modifying the structure of cell membranes, inducing the formation of microscopic, reversible pores without damaging cell functions. ${ }^{13}$ These temporary pores and other biomechanical alterations of the cell membrane provide the means for facilitated passage of drugs and their subsequent accumulation in intracellular compartments, as described elsewhere. ${ }^{14}$ The performance of various microbubble-assisted ultrasound chemotherapy systems has been evaluated both in vitro and in vivo, along with a growing number of preclinical experiments. ${ }^{12}$ Microbubbles and drugs like doxorubicin, paclitaxel, cisplatin, and cetuximab have been studied either as microbubble/drug-conjugated platforms or separately, using different regimens of ultrasound. ${ }^{15-19}$ Overall, these studies report increased intracellular drug concentrations leading to enhanced drug toxicity for cells sonoporated in the presence of drugs. Similar improvements have also been observed in vivo, revealing a significant reduction of tumor volume, decreased accumulation of drugs in the liver, and prolonged median survival in animal models, compared to ultrasound-free chemotherapy. ${ }^{12}$

Additionally, sonoporation has also been used to increase the uptake of magnetic nanoparticles by cancer cells, especially for imaging applications. The use of LIFU has led to enhanced localization of drug-loaded nanoparticles via magnetic resonance imaging (MRI) and increased magnetic labelling efficiency as a function of intracellular nanoparticle concentrations. ${ }^{20-22}$ Importantly, some studies have reported increased nanoparticle internalization after one-minute sonoporation using continuous ultrasound compared to $24 \mathrm{hr}$ standard incubation in the absence of LIFU. ${ }^{23}$ The mechanisms associated with ultrasound-assisted internalization of nanoparticles have suggested that sonoporation leads to noninternalizing uptake routes, reducing oxidative stress and minimizing long-term cytotoxicity of nanoparticles in healthy cells. ${ }^{24}$ Therefore, ultrasound provides a promising outlook in cancer treatment by improving drug/nanoparticle delivery, yet its incorporation as an integrated component in drug/MFH combination treatments has not been reported.

Motivated by the need to improve drug and nanoparticle accumulation for more efficient drug/MFH platforms, the present work suggests the use of microbubble-assisted ultrasound to potentiate the cell-killing profile of MFH/ PES combination treatments. It was hypothesized that cancer cells exposed LIFU in the presence of PES and 
nanoparticles, would increase the drug intracellular concentration, while improving nanoparticle distribution, thus leading to superior cancer cell killing profile after exposure to AMF. To test our hypothesis, the experimental design started with the evaluation of the three individual therapies: microbubble-mediated ultrasound (US), magnetic fluid hyperthermia (MFH), and drug (PES), at experimental conditions nearly innocuous for cell viability. Results showed that ultrasound is a novel approach to expand the benefits of thermal potentiation of PES via magnetic heating, leading to superior cell killing profiles in ovarian cancer cells.

\section{Materials and Methods Materials}

Roswell Park Memorial Institute (RPMI) 1640 culture medium, sodium bicarbonate, gentamicin solution, phosphate buffered saline (PBS), Trypan Blue, Trypsin-EDTA 0.25\%, hydroxylamine hydrochloride, sodium acetate, 1,10phenanthroline monohydrate, ICP iron standard, EDTA $5 \mathrm{Mm}$ solution, and 2-phenylethynesulfonamide (PES) were purchased from Sigma Aldrich (St. Louis, MO). Nitric acid $70 \% \mathrm{v} / \mathrm{v}$ (Optima grade) and ethanol absolute were purchased from Fisher Scientific (Hampton, New Hampshire). Fetal bovine serum (FBS), Sytox Green nucleic acid stain, Hoechst ${ }^{\circledR}$ 3342, and Hanks balanced salt solution (HBSS) were purchased from Life Technologies/Thermo Fisher Scientific (Waltham, MA). Calcein-AM kit was purchased from Nexcelom Biosciences (Lawrence, Massachusetts). Definity ${ }^{\circledR}$ microbubbles were donated by Lantheus Medical Imaging (North Billerica, MA). All reagents were used as received or as indicated by the manufacturer.

\section{Cell Cultures}

HeyA8ip1 human ovarian carcinoma cells were provided by the institutional Cell Line Core Laboratory at MD Anderson Cancer Center. Cells were cultured on $75 \mathrm{~cm}^{2}$ flasks (Eppendorf, Hamburg, Germany) with RPMI 1640 medium supplemented with $15 \% \mathrm{FBS}, 2 \mathrm{~g} / \mathrm{L}$ sodium bicarbonate, $0.1 \%$ gentamicin, and maintained at $37^{\circ} \mathrm{C}$ and $5 \% \mathrm{CO}_{2}$ as described elsewhere. ${ }^{11}$ Cells were split every 3 days at a 1:3 split ratio with an $80-90 \%$ of confluence, keeping passage numbers below twenty.

\section{Nanoparticle Suspension}

Iron oxide magnetic nanoparticles were synthesized and coated with silanized polyethylene glycol (PEG) following methods from previous publications. ${ }^{25,26}$ Here is summarized the synthesis, surface modification, and characterization. Briefly, iron (II) and iron (III) solutions (0.30 M total iron concentration) were reacted under a nitrogen atmosphere with ammonium hydroxide at $85^{\circ} \mathrm{C}$ and $\mathrm{pH}$ between 8.0 and 9.0 for $1 \mathrm{hr}$. The resultant iron oxide solution (IO) was cooled and peptized twice with tetramethylammonium hydroxide (TMAOH) using a high energy sonication probe for 20 mins. Peptized nanoparticles were centrifuged, magnetically decanted, and suspended in deionized water. Afterwards, oleic acid (OA) was reacted with nanoparticles $(25 \mathrm{mg} / \mathrm{mL})$ at $50^{\circ} \mathrm{C}$ for $2 \mathrm{hrs}$, washed with absolute ethanol, and dispersed in toluene. The OA layer was then exchanged by PEG-Silane, prepared as described elsewhere, ${ }^{27}$ and stirred for $72 \mathrm{hrs}$ at room temperature. PEG-coated nanoparticles were precipitated with cold diethyl ether, washed with acetone, magnetically decanted, and dried in a vacuum oven at room temperature. Physical and hydrodynamic diameters were determined by transmission electron microscopy (200CX, JEOL, Akishima, Japan) and dynamic light scattering (Zeta PALS, Brookhaven Instruments, Holtsville, NY), respectively. Magnetic behavior was measured using a superconducting quantum interference device - SQuID magnetometer (MPMS3, Quantum Design, San Diego, CA). The specific absorption rate (SAR) was determined via induction heating (EasyHeat 8310 LI, Ambrell, Hengelo, Netherlands) and normalized by iron content quantified by UV-Vis spectrophotometry (UV-2600, Shimadzu Scientific Instruments, Inc., Kyoto, Japan). The surface charge and weight percentage of iron oxide core were determined using zeta potential via particle size analyzer (Zeta PALS, Brookhaven Instruments, Holtsville, NY) and thermogravimetric analysis (TA Instruments Q 6000 STD, New Castle, DE), respectively. PEG-coated nanoparticle aqueous suspensions were purified by dialysis against deionized water, concentrated using Amicon filter units, and sterilized using sterile syringe filters of $0.20 \mu \mathrm{m}$. The final particle concentration used in experiments was $0.6 \mathrm{mg} \mathrm{IO} / \mathrm{mL}$.

\section{Focused Ultrasound Design and Calibration}

A single-element-focused ultrasound transducer (H-115, Concepts $^{\circledR}$, Bothell, WA) was assembled to a coupling, truncated cone and filled with degassed, deionized water. The transducer-cone assembly was characterized using an HNR-100 needle hydrophone (Onda Corp, Sunnyvale, CA) to experimentally determine the position on the 
circular target region at which the ultrasound intensity is maximum. The experimental setup for the calibration is very similar to that reported by Rodríguez-Negrón ${ }^{28}$ with slight modifications. Pressure measurements were performed along the circular target region and along the vertical axis, starting at $40 \mathrm{~mm}$ from the transducer up to $60 \mathrm{~mm}$. All measurements were performed at steps of $1 \mathrm{~mm}$, at a fixed amplitude of $1 \mathrm{~V}$ and center frequency of $1.1 \mathrm{MHz}$. The acoustic intensity was obtained from the pressure values according to the following equation:

$$
I=\frac{P^{2}}{2 * Z *(100)^{2}}
$$

where $\mathrm{P}$ is the peak pressure, $\mathrm{Z}$ is the acoustic impedance of water $\left(1.48 \mathrm{~kg} / \mathrm{s}^{*} \mathrm{~m}^{2}\right)$, and $100^{2}$ is the correction factor required to express the acoustic intensity in $\mathrm{W} / \mathrm{cm}^{2}$. When using pulsed ultrasound, the acoustic intensity varies with time thus it is reported as the spatial peak temporal average intensity, $\mathrm{I}_{\mathrm{SPTA}}$, obtained the acoustic intensity is multiplied by the duty cycle. Mapping of acoustic intensity is shown in Figure SI-1.

\section{Optimization of Ultrasound Parameters}

Cells were seeded in $35 \mathrm{~mm}$ petri dishes $18 \mathrm{hrs}$ before the experiments (cell populations ranged from $1 \times 10^{5}$ to $1 \times 10^{6}$ cells). The ultrasound transducer was filled with deionized, degassed water and sealed with a latex membrane. Definity ${ }^{\circledR}$ microbubbles (MB) in RPMI/FBS $15 \%\left(\sim 2.5 \times 10^{7} \mathrm{MB} / \mathrm{mL}\right.$ or up to $66 \mathrm{MB} /$ cell) were added to cells right before ultrasound exposure. Using a thin layer of ultrasound coupling gel between the latex membrane and petri dishes, cells were exposed to either continuous or pulsed ultrasound for times ranging in 30-60 s, at intensities ranging from 2 to $5 \mathrm{~W} / \mathrm{cm}^{2}$ (or up to $16.3 \mathrm{~W} / \mathrm{cm}^{2}$ for some experiments). For pulsed ultrasound, the pulsed repetition period (PRP) and duty cycle (DC) were fixed at $1.0 \mathrm{~ms}$ and $30 \%$, respectively. Once sonicated, cells were detached with trypsin and automatically counted using Trypan Blue live/dead cell exclusion. Results were processed as a viability ratio with respect to control groups without ultrasound exposure (number of cells of treated groups/number of cells of the control group). Experiments were performed in triplicate.

\section{Assessment of Cell Membrane Permeabilization}

Five hundred thousand cells were seeded in $35 \mathrm{~mm}$ petri dishes $18 \mathrm{hrs}$ before the experiments. A cocktail of $2 \mu \mathrm{M}$
SYTOX Green ${ }^{\circledR}$, Hoechst $33342(10 \mathrm{mg} / \mathrm{mL})$, and Definity ${ }^{\circledR}$ microbubbles (66 MB/cell) was added to petri dishes, followed by exposure to pulsed ultrasound $(\mathrm{PRP}=1.0 \mathrm{~ms}, \mathrm{DC}=$ $30 \%)$ in the dark. Four experimental groups were studied varying the intensity $\left(\mathrm{I}_{\mathrm{SPTA}}\right)$ and the ultrasound exposure time $\left(t_{U S}\right)$. After ultrasound exposure, cells were incubated at $37^{\circ} \mathrm{C}$ minutes in the dark, washed with HBSS four times, and subsequently imaged using an inverted fluorescence microscope (CKX53, Olympus, Tokyo, Japan). Pictures were taken using a 20X objective and a cooled, color camera (DP74 CMOS, Olympus, Tokyo, Japan). Images were processed using CellSens standard imaging software version 1.14 (CellSens, Zuid-Holland, Netherlands) showing cell nuclei in blue and viable cells with permeabilized cell membranes as green fluorescent cells.

\section{Internalization of Magnetic Nanoparticles}

One million cells were seeded in $35 \mathrm{~mm}$ petri dishes $18 \mathrm{hrs}$ before the experiment. Definity ${ }^{\circledR}$ microbubbles $(66 \mathrm{MB} / \mathrm{cell})$ were added to a nanoparticle suspension $[0.6 \mathrm{mg} \mathrm{IO} / \mathrm{mL}]$ prepared in RPMI/FBS $15 \%$ and added to petri dishes. Cells from experimental groups (US) were exposed to pulsed ultrasound $(\mathrm{PRP}=1.0 \mathrm{~ms}, \mathrm{DC}=30 \%)$ at $\mathrm{I}_{\mathrm{SPTA}}$ values of 1.8 and 2.5 $\mathrm{W} / \mathrm{cm}^{2}$, and $\mathrm{t}_{\mathrm{US}}$ of 20 and $40 \mathrm{~s}$. Cells from control groups (nonUS) received the microbubble/nanoparticle mixture but were not exposed to ultrasound. Both control and experimental groups were incubated for 5 or $12 \mathrm{hrs}$ at $37^{\circ} \mathrm{C}$. Once the incubation time ended cells were washed twice with PBS, rinsed with EDTA, detached using vigorous pipetting, and counted using an automated cell counter (Auto T4, Nexcelom Bioscience, Lawrence, Massachusetts). Live/dead cell populations were assayed via Trypan Blue exclusion dye under brightfield. Detached cells were digested with nitric acid $70 \%(1.0 \mathrm{~mL} \mathrm{HNO} 3 /$ million cells $)$ at $101{ }^{\circ} \mathrm{C}$ overnight until complete acid evaporation. Then, $46 \mu \mathrm{L}$ of deionized water was added, followed by $30 \mu \mathrm{L}$ of hydroxylamine hydrochloride $[8.6 \mathrm{M}]$. After $1 \mathrm{hr}$ of iron reduction, 49 and $75 \mu \mathrm{L}$ of sodium acetate $[1.22 \mathrm{M}]$ and 1.10 -phenanthroline [13 $\mathrm{mM}$ ], respectively, were added. The absorbance $(508 \mathrm{~nm})$ was measured using a UV/Vis absorbance microplate reader (Infinite M200 PRO, Tecan, Männedorf, Switzerland). All experiments were performed in triplicate.

\section{US/MFH/PES Individual and Combination Treatments}

Five hundred thousand cells were seeded in $35 \mathrm{~mm}$ petri dishes $18 \mathrm{hrs}$ before the experiment. Nanoparticles, Definity ${ }^{\mathbb{B}}$ 
microbubbles, and/or PES at concentrations $0.6 \mathrm{mg} \mathrm{IO} / \mathrm{mL}, 66$ $\mathrm{MB} /$ cell and $10 \mu \mathrm{M}$, respectively, were added to cells. Various experimental groups were created based on the individual treatments and their combinations, according to the experimental design shown in Figure 1. Cells from experimental groups involving ultrasound as dual or triple combinations were sonicated using pulsed ultrasound, $\mathrm{PRP}=1.0 \mathrm{~ms}, \mathrm{t}_{\mathrm{US}}=$ $60 \mathrm{~s}, \mathrm{DC}=30 \%, \mathrm{I}_{\mathrm{SPTA}}=1.8 \mathrm{~W} / \mathrm{cm}^{2}$. Cells were incubated at $37^{\circ} \mathrm{C}$ either for 0.5 or $12 \mathrm{hrs}$ after ultrasound treatment. Then, cells were exposed to an AMF for 30 mins using an induction heater (EasyHeat 8310 LI, Ambrell, Scottsville, NY) equipped with a six-loop coil (2.5" diameter x 2 " length) cooled by tap water at $14^{\circ} \mathrm{C}$. Temperatures of liquid media inside petri dishes, the coil, and the surrounding temperature were monitored by a DAQ system (National Instruments, Austin, TX) and type-T thermocouples (model 5TC-TT-T-40-72, Omega, Stamford, CT). Temperature-time data were stored in a computer via LabView ${ }^{\mathrm{TM}} 14.0$ software (National Instruments, Austin, TX). AMF exposure was performed for 30 mins at $37^{\circ} \mathrm{C}$, and frequency $\mathrm{f}=245 \mathrm{kHz}$ and magnetic field intensity $\mathrm{H}_{\mathrm{o}}=15-20 \mathrm{kA} / \mathrm{m}$ to achieve sustained temperatures of $41^{\circ} \mathrm{C}$ or $43^{\circ} \mathrm{C}$. Once the magnetic exposure finished, cells were washed with RPMI/FBS $15 \%$ to remove nanoparticles, drug and microbubbles, and then fresh culture medium and/or drug were added, followed by incubation for $48 \mathrm{hrs}$ at $37^{\circ} \mathrm{C}$ and $5 \% \mathrm{CO}_{2}$. Cells were washed, detached with trypsin, and counted using two methods: a) manual/automatic cell count with Trypan Blue live/dead exclusion and b) automatic, fluorescent cell count (Vision, Nexcelom Bioscience, Lawrence, MA) using Calcein-AM dye to identify metabolically active

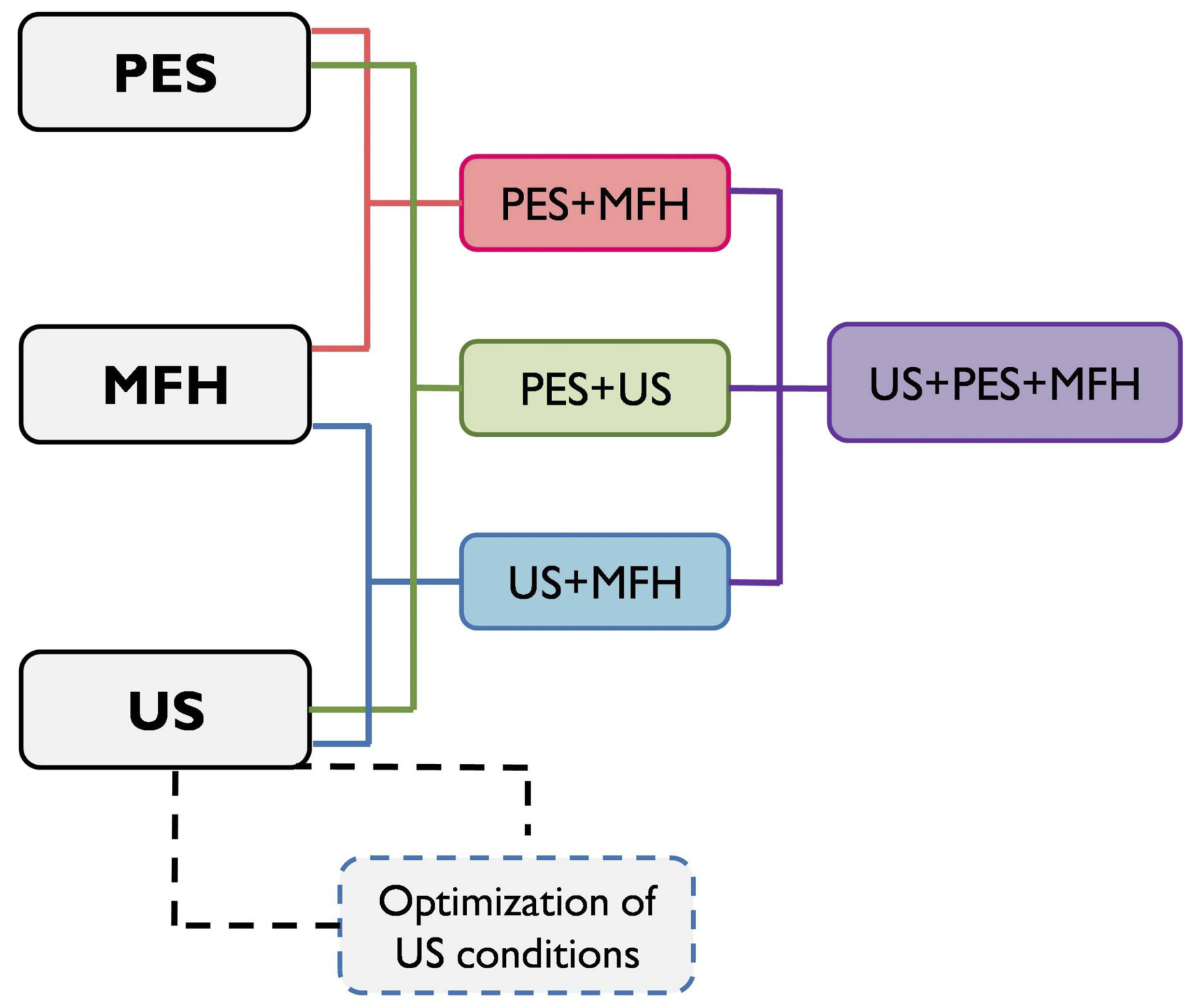

Figure I Overview of experimental design for individual or combination treatments between 2-phenylethynesulfonamide (PES), magnetic fluid hyperthermia (MFH) and ultrasound (US). Response variable is cell viability. 
cells, emitting green fluorescence. Cell viability ratios were determined with respect to the control (cells without any treatment). All experiments were run in triplicate.

\section{Statistical Analysis}

The sample size was $\mathrm{n}=3$ for all experiments except for fluorescence microscopy $(n=2)$. Bars represent the mean of replicates for each experiment and standard deviations were used as error bars. Statistical analysis was estimated using the Student's $t$-test (two-tailed distribution, twosample with unequal variance), considering significant differences at $P<0.05$.

\section{Results}

\section{Nanoparticle Characterization}

Physicochemical and magnetic properties of PEG-coated nanoparticles were evaluated, including particle size, magnetic behavior, surface charge, heat dissipation, and the amount of polymer grafted to particles. The results are shown in Figure SI-2. TEM analysis revealed that the physical diameter of nanoparticles is $15 \mathrm{~nm}$ which agrees with the range of physical size obtained for uncoated nanoparticles. Hydrodynamic diameters revealed particle sizes of $\sim 50-60 \mathrm{~nm}$ which is slightly higher than the diameters of uncoated nanoparticles. Such an increase was attributed to the layer of PEG-Silane grafted onto the nanoparticle's surface as it has been reported by others with increments of about $13 \mathrm{~nm}$ after coating nanoparticles with PEG-Silane of the same molecular weight. ${ }^{29}$ Equilibrium magnetization measurements at room temperature confirmed the superparamagnetic behavior of nanoparticles with saturation magnetization close to the bulk value for iron oxide. ${ }^{30}$ The surface charge of nanoparticles was very close to neutral at $\mathrm{pH} 7$, as demonstrated by zeta potential measurements. Nanoparticles became slightly negative at higher $\mathrm{pH}$ values because of abundant deprotonated amines in silanol groups at alkaline $\mathrm{pH}$. A specific absorption rate (SAR) value of $402 \mathrm{~W} / \mathrm{g}_{\mathrm{Fe}}$ was determined at $\mathrm{H}_{\mathrm{o}}=36.5 \mathrm{kA} / \mathrm{m}$ and $\mathrm{f}=345 \mathrm{kHz}$, which denotes a reduction of $23 \%$ of the heating efficiency with respect of the uncoated inorganic core, reported elsewhere. ${ }^{25}$ Reductions in SAR due to polymer coatings are attributed to the decreased Brownian loss due to increased hydrodynamic diameter. ${ }^{31}$ Thermogravimetric measurements revealed that PEG-coated nanoparticles were comprised of approximately $18 \%$ weight of iron oxide, consistent with previous observations for particles coated with PEG-Silane of the same molecular weight and similar experimental conditions for particle coating. ${ }^{29}$

\section{Optimization of Ultrasound Conditions}

The effect of continuous/pulsed ultrasound, acoustic intensity, exposure time, and cell population was evaluated on ovarian cancer cell viability using cell populations ranging in $1.5-2.0 \times 10^{6}$ cells. The results are shown in Figure SI-3. Continuous ultrasound caused cell detachment, leading to reductions in the number of adherent cells, even at acoustic intensities as low as $2 \mathrm{~W} / \mathrm{cm}^{2}$. Cell detachment due to continuous pulses was influenced by experimental conditions, but it was also a cell type-dependent phenomenon. ${ }^{13}$ Differently, a single application of pulsed ultrasound did not induce cell detachment at the studied intensity values and exposure times, thus making it potentially useful for further experiments. However, a second ultrasound exposure $1 \mathrm{hr}$ after the first sonication led to cell detachment, indicating that subsequent ultrasound exposures were not recommended. The exposure time was adjusted as a function of acoustic intensity, using smaller exposure times as the intensity increased. There was no difference between 30 and 60 seconds of ultrasound exposure time. As a result, the acoustic intensity and pulse type were the most influential parameters affecting cell viability. Additional experiments were conducted to evaluate the effect of various ultrasound schedules using lower cell populations, for example, those in the range of $1.0-5.0 \times 10^{5}$ cells. The lowest cell population $\left(1 \times 10^{5}\right.$ cells) showed high susceptibility to cell detachment when sonicated at intensities $\mathrm{I}_{\text {SPTA }}>0.9 \mathrm{~W} / \mathrm{cm}^{2}$. Overall, cell detachment correlated with increasing acoustic pressure. Cell populations consisting of $5 \times 10^{5}$ cells exposed up to $\mathrm{I}_{\mathrm{SPTA}}=2.5 \mathrm{~W} / \mathrm{cm}^{2}$ resulted in no major cell detachment. This parameter was identified as the threshold for subsequent experiments. Larger cell populations (eg, $1 \times 10^{6}$ cells) were observed to withstand $\mathrm{I}_{\mathrm{SPTA}}$ values as high as $3.6 \mathrm{~W} / \mathrm{cm}^{2}$ but beyond that point, major cell detachment was observed even for large cell populations. Interestingly, most cells that detached from culture dishes during sonication were able to reattach when transferred to new dishes, remaining viable. This was observed even for low cell numbers at $\mathrm{I}_{\mathrm{SPTA}}$ values up to $3.6 \mathrm{~W} / \mathrm{cm}^{2}$, but for higher intensities regardless of the cell population.

\section{Effect of Ultrasound-Induced Cell Membrane Permeabilization}

Cell membrane permeabilization was assessed via Sytox Green uptake at various combinations of acoustic intensities 
and exposure times. Sytox Green is virtually non-fluorescent in aqueous solutions and impermeable to intact cell membranes. When cells have temporally or permanently compromised membranes, the dye penetrates cells emitting brilliant, green fluorescence upon binding to nucleic acids. As illustrated in Figure 2, green fluorescence was observed in cells treated with different regimens of ultrasound (conditions A to D) when compared to the control (non-sonicated cells). Hoechst 33,342 was simultaneously used to stain the nuclei of all cells for visualization purposes. The highest levels of green fluorescence were visualized in cells that were exposed to ultrasound at $\mathrm{I}_{\mathrm{SPTA}}=1.8 \mathrm{~W} / \mathrm{cm}^{2}$ for $40 \mathrm{~s}$ (condition $\mathrm{B}$ ), while higher intensities led to reductions in green fluorescence. Therefore, condition B was chosen as the combination of acoustic intensity and exposure time to induce optimal cell membrane permeabilization in cells. At $\mathrm{I}_{\mathrm{SPTA}}$ of $2.5 \mathrm{~W} / \mathrm{cm}^{2}$ (conditions $\mathrm{C}$ and $\mathrm{D}$ ), the effect of exposure time becomes irrelevant as the levels of green fluorescence decreased when compared to conditions $\mathrm{A}$ and $\mathrm{B}$, regardless of the ultrasound exposure time. Even when the chance of labeling apoptotic cells with green fluorescence exists, fluorescence levels between viable and dying cells are different, which allows the identification of live, viable cells. ${ }^{32}$

\section{Internalization of Magnetic Nanoparticles}

The effect of ultrasound on nanoparticle internalization was studied using the same intensity-exposure time combination schedules assessed during Sytox Green uptake experiments. This allowed to quantitatively confirm whether optimal conditions that led to maximal uptake of Sytox Green were applicable to improve nanoparticle intracellular distribution. Also, additional incubation with nanoparticles after ultrasound exposure was performed at various timepoints to investigate the effect of cumulative nanoparticle uptake by cells. The cellular uptake of iron was quantified for sonicated cells in the presence of nanoparticles and subsequently incubated for 5 or $12 \mathrm{hrs}$ in nanoparticle suspension. Results are illustrated in Figure 3 for various US groups and the non-US (control group). It can be noted that in the absence of ultrasound, nanoparticles were internalized into cells in a time-dependent fashion, via non-specific uptake. Such behavior was observed when experiments were conducted using various incubation times with three different ovarian cancer cell lines (see Figure SI-4). Four US groups showed improvements in nanoparticle internalization when compared to the control. Interestingly, cells sonicated at $\mathrm{I}_{\mathrm{SPTA}}$ of $1.8 \mathrm{~W} / \mathrm{cm}^{2}$ for $40 \mathrm{~s}$ revealed the highest uptake of iron with values up to
3.7 and $11.4 \rho g_{\mathrm{Fe}} /$ cell for 5 and $12 \mathrm{hrs}$ of incubation time with nanoparticles, respectively. Improvements in cellular uptake of iron induced by ultrasound can also be expressed by comparing uptake values as the ratio of US groups divided by the non-US group, as summarized in Table 1. Hence, it was found that the amount of internalized nanoparticles was up to 1.6 to 1.8 times higher than those of the control group. These significant improvements occurred for incubation times with nanoparticles of 5 or $12 \mathrm{hrs}$ after ultrasound exposure. Therefore, the increased internalization due to ultrasound occurred independently of the total incubation time with nanoparticles.

\section{US/MFH/PES Combination Treatments}

Once optimal ultrasound conditions were identified, the effects of individual and combined treatments of ultrasound (US), drug (PES), and magnetic hyperthermia (MFH) were evaluated. Combination treatments were carried out under experimental conditions causing minimal damage to cells, mimicking clinical settings characterized by mild hyperthermia (41 C), low drug concentrations in tumors, and low acoustic intensities required for therapeutic ultrasound. However, moderate hyperthermia $\left(43^{\circ} \mathrm{C}\right)$ was also investigated to account for treatment approaches leading to maximal cytotoxic effects. Incubation of cells with various PES concentrations showed that $10 \mu \mathrm{M}$ is not toxic for cells and that inhibitory concentrations $\left(\mathrm{IC}_{50}\right)$ of $28 \mu \mathrm{M}$ took place after 72 hrs of incubation with the drug (Figure SI-5-a). As for $\mathrm{MFH}$, evidence supports that HeyA8 cells exposed to AMF are only minimally affected at $41^{\circ} \mathrm{C} .{ }^{11,33}$ At higher temperatures (i.e., $43^{\circ} \mathrm{C}$ and $45^{\circ} \mathrm{C}$ ) this work showed that ovarian cancer cell viability is strongly affected in a celldependent fashion (Figure SI-5-b). The effects of various individual and combination treatments are depicted in Figure 4 comparing mild and moderate hyperthermia conditions. When cells were exposed to ultrasound in the presence of the drug (US+PES) cell viability was significantly reduced by $37 \%$ compared to the non-toxic effect of PES and US administered individually. Similarly, when cells were exposed to ultrasound in the presence of magnetic nanoparticles and subsequently exposed to $\mathrm{AMF}$ at $41^{\circ} \mathrm{C}$ (US $+\mathrm{MFH}$ ), cell viability decreased by an additional $18 \%$ compared to viability obtained for MFH alone. Additional cell groups were treated with PES for $12 \mathrm{hrs}$ and subsequently exposed to $\mathrm{MFH}$ at $41^{\circ} \mathrm{C}$ and $43^{\circ} \mathrm{C}$ (PES+MFH) to investigate the effect of thermal energy using non-cytotoxic PES concentrations. Results from mild hyperthermia experiments revealed that cell viability decreased by an additional $36 \%$ 


\section{No US}

Sytox Green

Hoechst 33342

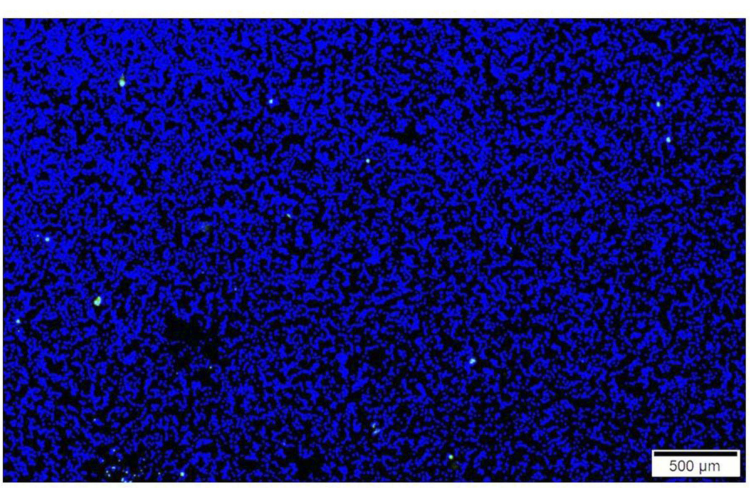

$$
\mathrm{I}_{\mathrm{SPTA}}=1.8 \mathrm{~W} / \mathrm{cm}^{2}
$$

$$
\mathrm{I}_{\mathrm{SPTA}}=2.5 \mathrm{~W} / \mathrm{cm}^{2}
$$

A

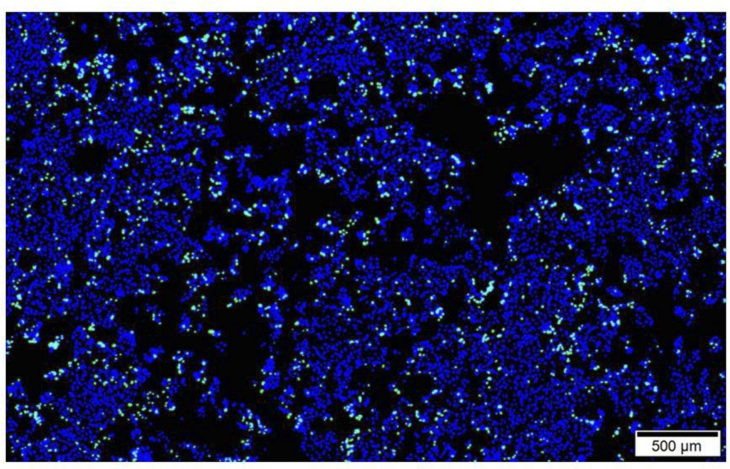

B

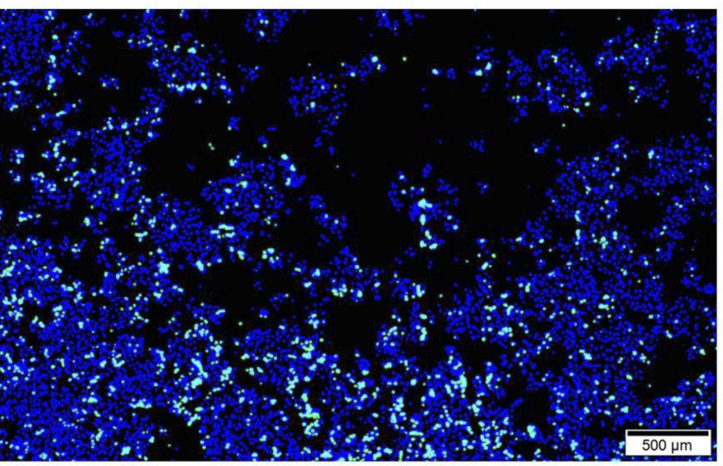

C

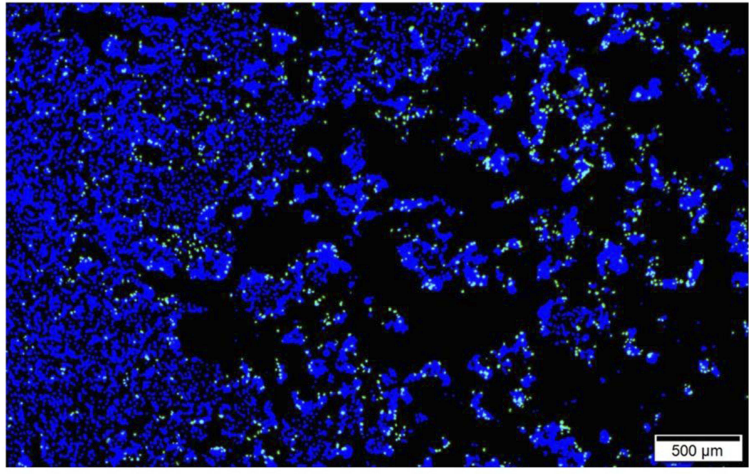

D

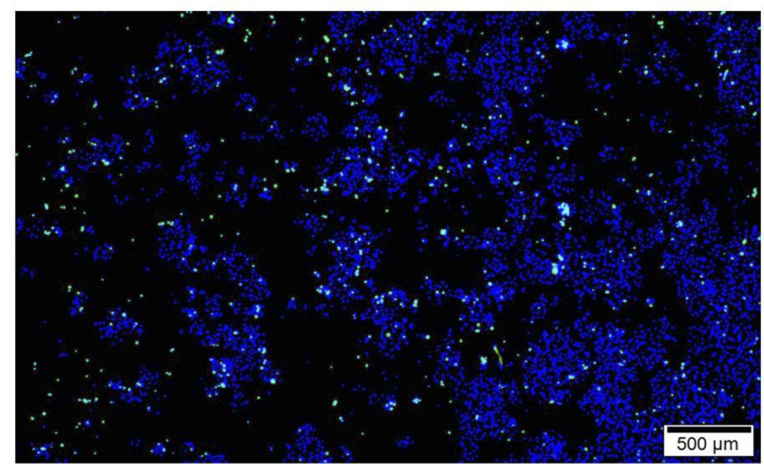

Figure 2 Live-cell fluorescence microscopy for the assessment ultrasound-induced cell membrane permeabilization via Sytox Green uptake by HeyA8 cells. Conditions (A-D) represent various combinations of $\mathrm{I}_{\text {SPTA }}$ values and exposure time. Images show one of the four representative areas evaluated per each sample. Scale bars represent $500 \mu \mathrm{m}$.

and $19 \%$ relative to viabilities obtained from PES and MFH individual treatments, respectively. Similar results were obtained for moderate hyperthermia, where cell viability decreased by an additional $21 \%$ compared to $\mathrm{MFH}$ alone. As expected, the effects of moderate hyperthermia were distinctively higher than those observed at $41^{\circ} \mathrm{C}$, with cell viability dropping down to 0.2 for $\mathrm{MFH}+\mathrm{PES}$. The effect of ultrasound was ultimately studied in a triple combination treatment carried out by sonicating cells in the presence of PES and nanoparticles, followed by AMF exposure to 12- hr post sonication (US+PES+MFH). A remarkable increase in cancer cell death took place compared to the group PES 


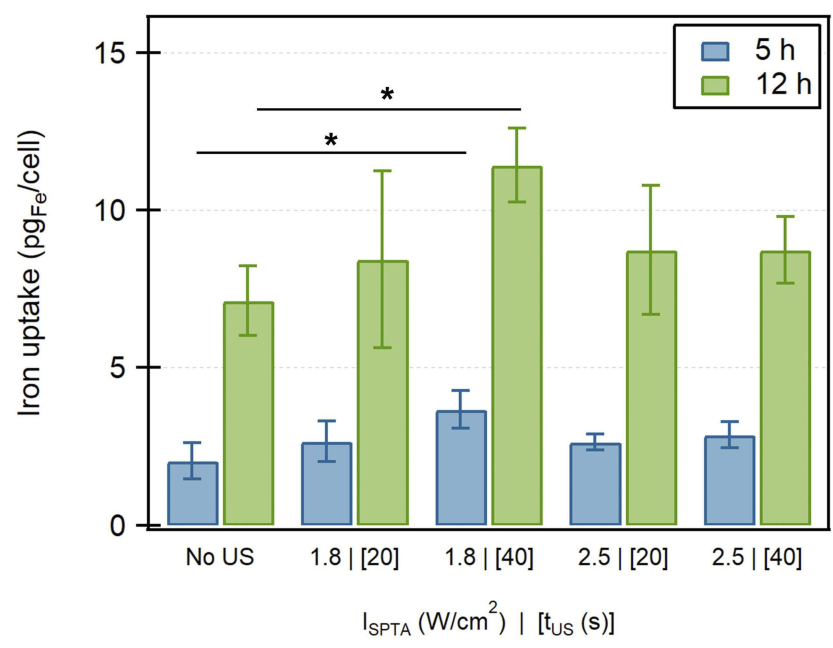

Figure 3 Ultrasound-assisted nanoparticle internalization into HeyA8 cells as a function of various spatial peak temporal average intensities (ISPTA) values | [exposure time $\left(t_{u s}\right)$ ] conditions. Cells were incubated with nanoparticles for 5 or 12 hrs. Error bars represent the standard deviation of three independent experiments. ${ }^{*}$ Represents significantly different values ( $p$-values $\left.<0.05\right)$.

+ MFH with cell viability decreased by an additional $26 \%$. These observations are consistent with the hypothesis that improved cancer cell killing profiles could be achieved when using ultrasound to enhance the effects of MFH and PES. In the case of moderate hyperthermia, no significant difference was observed between groups PES+MFH and US+PES $+\mathrm{MFH}$ since $\mathrm{MFH}$ alone at $43^{\circ} \mathrm{C}$ is more aggressive, thus leading to small numbers of viable cells after treatment. Comparisons between groups with very small cell numbers made it difficult to distinguish whether significant differences were obtained or not, disguising relevant findings. For this reason, it was decided to continue subsequent studies using only mild hyperthermia.

The objective of exposing cells to AMF $12 \mathrm{hrs}$ after sonication was to allow sufficient time for drugs and nanoparticles to cross permeabilized membranes via facilitated transport through pores on the cell membrane. Yet, results from ultrasound-assisted nanoparticle internalization indicated that net improvements in the cellular uptake of iron between 5 - or

Table I Normalized Iron Uptake Values Expressed as the Ratio Between the Ultrasound-Assisted Internalization Divided by Internalization in the Absence of Ultrasound (US/Non-US)

\begin{tabular}{|c|c|c|}
\hline$I_{\text {SPTA }}, W / \mathrm{cm}^{2} \mid\left[t_{\text {US }}, s\right]$ & 5 hrs & $12 \mathrm{hrs}$ \\
\hline $1.8 \mid[20]$ & 1.3 & 1.2 \\
\hline $1.8 \mid[40]$ & 1.8 & 1.6 \\
\hline $2.5 \mid[20]$ & 1.3 & 1.2 \\
\hline $2.5 \mid[40]$ & 1.4 & 1.2 \\
\hline
\end{tabular}

Abbreviation: ISPTA, spatial peak temporal average intensity.

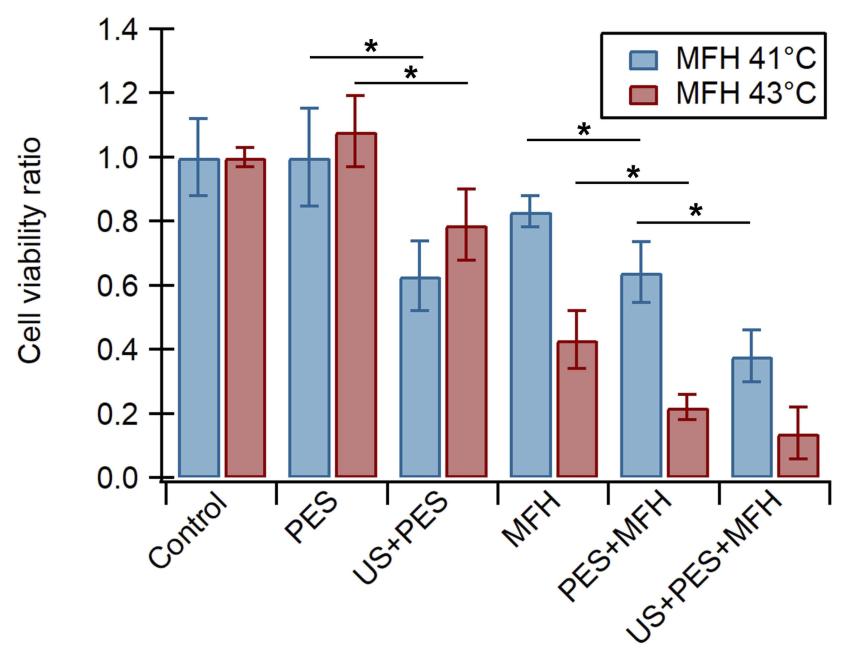

Figure 4 Viability ratio of HeyA8 cells after combination treatments of ultrasound (US), drug (PES) and hyperthermia (MFH) at mild and moderate hyperthermia temperatures. AMF conditions were $\mathrm{H}_{\circ}=15-20 \mathrm{kA} / \mathrm{m}, \mathrm{f}=245 \mathrm{kHz}$, exposure time: $30 \mathrm{~min}$. Cells were sonicated $12 \mathrm{hrs}$ before AMF exposure. Error bars represent the standard deviation of three independent experiments. *Represents significantly different values ( $p$-values $<0.05$ ).

12-hr post-sonications were not significant. Therefore, it was assumed that incubation times with nanoparticles for several hours were no longer required and the same would likely apply for PES. Aiming to confirm this premise, additional MFH experiments at $41^{\circ} \mathrm{C}$ were conducted with the same experimental groups but applying ultrasound 30 mins before AMF exposure. As shown in Figure 5, the tendency of combination treatments was very similar to that of experiments comprised of sonications $12 \mathrm{hrs}$ before AMF exposure, and the correlation of increased cell death with the incorporation of

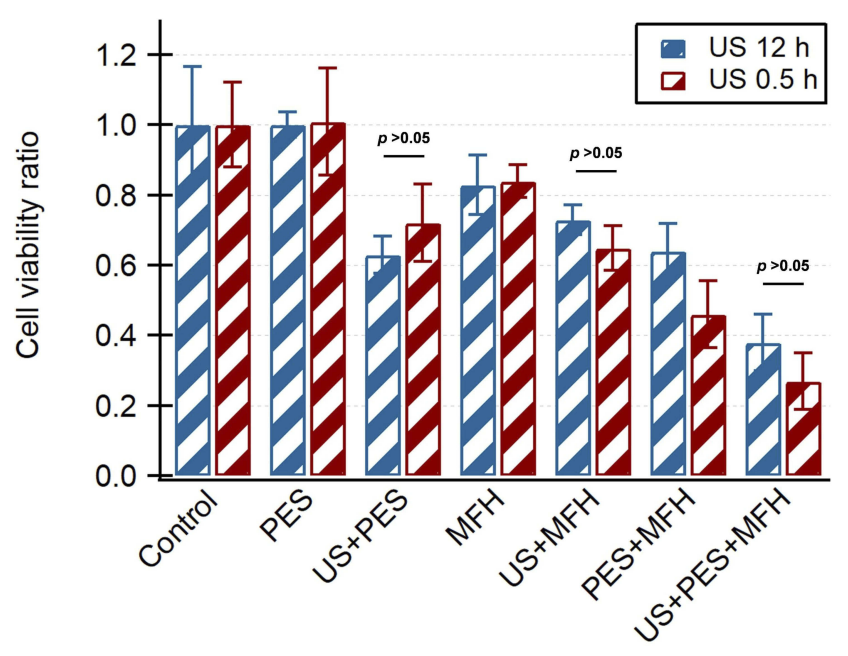

Figure 5 Comparison of US/PES/MFH combination therapies with bulk heating at $41^{\circ} \mathrm{C}$. Cells were sonicated either $12 \mathrm{hrs}$ (blue bars) or 30 mins (red bars) before exposure to AMF $\left(\mathrm{H}_{\circ}=15-20 \mathrm{kA} / \mathrm{m}, \mathrm{f}=245 \mathrm{kHz}\right.$, exposure time $\left.=30 \mathrm{~min}\right)$. Error bars represent the standard deviation of three independent experiments. 
ultrasound was consistently observed. Moreover, it was confirmed that reducing the time between sonications and AMF exposure resulted in no significant differences for the various combination treatments including ultrasound exposure ( $p$-values $>0.05$ ). Therefore, it was confirmed that ultrasonic potentiation of PES+MFH can be consistently achieved, and that it can be applied right before AMF exposure yet having the same beneficial outcome. The concurrent administration of ultrasound, PES and MFH induced major cell death when compared to individual or dual treatments, driven by improved intracellular delivery of PES and enhanced nanoparticle internalization, attained with ultrasound.

\section{Discussion}

Optimization of ultrasound parameters was an important component of this work to ensure stable cavitation during sonoporation without thermal effects, minimizing cell detachment, yet inducing reversible cell membrane permeabilization. Ultrasound-induced hyperthermia and inertial cavitation of microbubbles can be deleterious to cells, thus optimizing ultrasound parameters is required when designing ultrasound-based therapies. ${ }^{34}$ Our results show that cell numbers in the order of $1 \times 10^{5}$ were instantaneously detached from culture plates upon ultrasound exposure, whereas populations $\geq 5 \times 10^{5}$ cells were not affected. Such observations indicated that cell-to-cell interactions played an important role in response to stresses caused by microbubble cavitation. Cell detachment during ultrasound exposure could be a consequence of irreversible disassembly in tubulin networks triggered by disruption of microtubule integrity, as reported by Fan et al. ${ }^{35}$ Therefore, low cell populations with disrupted microtubules would be unable to recover from cytoskeleton damage compared to higher cell populations, where proximity stabilizes cell-to-cell interactions, possibly reversing tubulin disassembly. Ultrasound exposure at $\mathrm{I}_{\mathrm{SPTA}}$ and $\mathrm{t}_{\mathrm{US}}$ of $1.8 \mathrm{~W} / \mathrm{cm}^{2}$ and $40 \mathrm{~s}$, respectively, provided optimal conditions to induce cell membrane permeabilization with minimum cell detachment phenomena. Increasing $\mathrm{I}_{\mathrm{SPTA}}$ to $2.5 \mathrm{~W} / \mathrm{cm}^{2}$ led to cell detachment thus both blue and green fluorescence levels decreased. This observation does not indicate a reduction in cell membrane permeability, but the reduction in the overall number of fluorescent cells as depicted by the increase of dark spots in Figure 2, conditions $\mathrm{C}$ and $\mathrm{D}$, indicating areas with cell detachment. Yet, additional tests were conducted by transferring detached cells after ultrasound exposure at $2.5 \mathrm{~W} / \mathrm{cm}^{2}$ to petri dishes with fresh culture medium, and it was confirmed that detached cells remained viable even $48-\mathrm{hr}$ post sonication. Intensity and exposure times evaluated in this work are in agreement with safe dosimetry for therapeutic applications of ultrasound thus these values are translatable for clinical use. ${ }^{36}$ Results from fluorescence microscopy qualitatively demonstrated cell membrane permeabilization of viable cells by the high extent of green fluorescence emitted by cells via Sytox Green uptake. Some studies report that green fluorescence levels emitted by Sytox Green in viable, sonoporated cells are significantly higher than those emitted by passive loading of the dye in dead cells by diffusion. ${ }^{32}$ In addition, this work demonstrated that reductions in cell numbers immediately after ultrasound exposure were mostly due to cell detachment. Detached cells during sonication were eliminated along with the excess of fluorescent dyes via extensive washing prior to imaging. Therefore, it was presumed that green fluorescence observed in all groups was emitted only by viable cells.

Ultrasound conditions leading to optimal cell membrane permeabilization were also quantitatively confirmed via intracellular iron quantification. Notable improvements on iron uptake of up to $11.4 \rho_{\mathrm{Fe}} \mathrm{e}$ cell after 12-hr incubation with nanoparticles were observed with the incorporation of ultrasound. These high uptake values were the contribution of nanoparticles crossing the cell membrane via pore-mediated access and passive transport by non-specific uptake mechanisms. Even when non-specific uptake occurred in a timedependent fashion for both control and experimental groups, the net improvement in iron uptake was similar regardless of the total incubation time with nanoparticles. These observations suggest that nanoparticle transport through porated/permeabilized cell membranes takes place simultaneously with ultrasound exposure or shortly after it. For example, the work of Kolarova et al shows that improvements in iron uptake occurred as fast as one minute-post sonication compared to $24 \mathrm{hr}$ internalization without ultrasound. ${ }^{23}$ Non-specific uptake of PEG-coated nanoparticles by ovarian cancer cells has been ascribed to clathrin- and caveolae-mediated endocytic pathways with subsequent nanoparticle distribution in endosomes and lysosomes. ${ }^{37}$ Lower uptake values of cells sonicated at other acoustic intensities (eg I $\mathrm{SPTA} \geq 2.5 \mathrm{~W} / \mathrm{cm}^{2}$ ) may be associated with an impaired equilibrium between facilitated internalization and exocytosis during resealing of membrane pores. As explained by Lentacker et al, resealing of membrane pores may trigger exocytosis because of reduced membrane tension and intracellular vesicle trafficking. ${ }^{38}$ Hence, the use of higher acoustic intensities during 
experiments could lead to the formation of bigger membrane pores, which would require more time for healing, leading to losses of internalized molecules or nanoparticles. It is important to mention that sonoporation in the presence of nanoparticles was conducted to enhance nanoparticle uptake by cancer cells rather than using nanoparticles as cavitation media or heat transfer actuators. Some authors report the use of iron oxide and other metallic nanoparticles as sonosensitizers due to a combination of mechanical and thermal effects. ${ }^{39-41}$ These studies have demonstrated the efficiency of sonosensitization by the increased cancer cell death due to ultrasoundinduced hyperthermia, sometimes leading to thermal potentiation of chemotherapy in various combination treatments. ${ }^{42}$ Differently, our work used gas-filled microbubbles as cavitation media to induce biomechanical effects and ultrasound conditions were tuned up to minimize both cell detachment and thermal effects. The absence of thermal effects as a consequence of adjusting parameters such as duty cycle, ultrasound exposure time, and frequency has been reported by others with ultrasound settings similar to those used in this work. ${ }^{43-46}$ For example, our ultrasound exposure was pulsed at a duty cycle of $30 \%$ for $20-60 \mathrm{~s}$ compared to continuous ultrasound irradiation for 5-10 mins as reported in the studies referred before. Therefore, it is thought that the presence of nanoparticles during ultrasound irradiation did not contribute thermal effects and the main contribution to mechanical effect, most likely stable cavitation, produced by Definity ${ }^{\circledR}$ microbubbles in the culture medium.

The improved cell killing achieved upon the incorporation of ultrasound was attributed to the increased PES intracellular concentrations and increased nanoparticle uptake, due to cell sonoporation. Results from dual combination experiments were early indications that ultrasound potentiated the effect of otherwise non-toxic drug concentrations and enhanced the anticancer profile of mild hyperthermia at the studied conditions. Such events were clearly induced by ultrasound, but also the result of effects caused by individual therapies. For example, heat stress produced during MFH induces apoptosis and other cell death mechanisms including the immunogenic effects of heat-shock proteins (HSP) ${ }^{47,48}$ In addition, experimental evidence supports that mild magnetic hyperthermia increases cell membrane fluidity, leading to higher uptake of some chemotherapeutic drugs. ${ }^{6}$ These individual contributions may lead to significantly higher cell death through various mechanisms. First, the mechanical bioeffects of ultrasound on cell membranes, such as sonoporation, can be further enhanced by increased membrane fluidity caused by $\mathrm{MFH}$, as demonstrated elsewhere. ${ }^{6}$ Hence, the cytotoxic profile of US+MFH is lower than that of US+PES+MFH because the drug is not present in the medium. Yet, US $+\mathrm{MFH}$ induced more cell death than MFH alone because of the increased mechanical stress on the cell membrane caused by ultrasound. Therefore, the reason behind the increased cell death was not the effect of US alone, which does not affect cell viability as demonstrated during the optimization of ultrasound parameters. One possible reason is the intracellular, local heating effects caused by increased nanoparticle internalization as a result of cumulative stress on cell membranes (e.g., sonoporation from ultrasound plus increased membrane fluidity from MFH). Despite the arguments against nanoscale thermal phenomena, experimental evidence highlights the benefits of heating effects in the vicinity of magnetic nanoparticles, which could actually enhance the thermal potentiation of chemotherapeutic agents. ${ }^{3,49}$ Second, the mechanism of action of PES to induce cancer cell death can be further enhanced by one of the mechanisms triggered by MFH. PES inhibits the function of stress-inducible heat-shock proteins (HSP70 family), which support lysosome membrane integrity, though lysosomal membrane permeabilization has also been identified as one of the death pathways after exposure to AMF. ${ }^{50,51}$ In addition, experimental evidence reveals that the fate of PEG-coated nanoparticles may be accumulation in endosomes and lysosomes upon internalization in ovarian cancer cells via non-specific uptake. ${ }^{37}$ Our results indicated that slightly higher cell death occurred for PES+MFH compared to that of US+PES. We hypothesize that such a pattern is likely due to an increase in damage to lysosomal membranes caused by PES and intensified by MFH. The cytotoxic effect of PES+MFH at both mild and moderate hyperthermia was consistent with that previously reported by our group thus demonstrating that thermal potentiation of PES in ovarian cancer cells via MFH was reproducible. Our previous work not only demonstrated the synergy between PES and MFH in vitro but also antitumor efficacy of PES+MFH in orthotopic ovarian cancer models. ${ }^{11}$ Yet, the central goal of this work was to evaluate further improvements in PES+MFH combination treatments in vitro by using low-intensity ultrasound. Therefore, when ultrasound was incorporated to yield the triple combination group (US+PES+MFH), the cancer cell killing profile was substantially potentiated due to the increased PES and nanoparticle intracellular concentrations. Still, the cumulative effect on the structure of cell membranes due to mechanical and thermal stress could induce more drug/ 
nanoparticle transport across the cell membrane. At this point, it is evident that all these effects take place concurrently with causes and effects being part of a cycle that leads to potentiate cytotoxic effects on cells. Inherently, these effects are ruled by high PES intracellular concentrations along with improved nanoparticle penetration, achieved via ultrasound. Higher PES intracellular concentrations are likely to cause major rupture of lysosomal membranes as proposed elsewhere. ${ }^{11}$ Importantly, all these observations came from experiments carried out using a non-cytotoxic PES concentration which became toxic due to ultrasound. Furthermore, no significant differences were observed in cell viability for the temporal window of ultrasound and AMF exposure ( 0.5 or $12 \mathrm{hrs})$ thus indicating that ultrasound can be applied right before MFH. Results discussed in this work have demonstrated the ultrasonic potentiation of $\mathrm{PES} / \mathrm{MFH}$ combination treatments in vitro suggesting that similar efficacies could be potentially attained in vivo.

\section{Conclusion}

Significant improvements in ovarian cancer cell killing profiles were obtained with the incorporation of ultrasound on PES/MFH combination therapies at mild hyperthermia temperatures. The use of low-intensity ultrasound induced the occurrence of cell sonoporation which increased the intracellular delivery of PES, while improving nanoparticle internalization. The ultrasonic potentiation of $\mathrm{PES} / \mathrm{MFH}$ was achieved after the systematic optimization of ultrasound conditions to achieve maximum cell membrane permeability and minimum damage to cells during ultrasound exposure. To the best of our knowledge, this is the first time that lowintensity-focused ultrasound is used to potentiate the effects of magnetic fluid hyperthermia as an adjuvant in cancer chemotherapy. It was demonstrated that the cytotoxic profile of the HSP70 inhibitor PES can be greatly potentiated by the concomitant administration of thermal and mechanical energy, using an in vitro ovariatablen cancer model. Hence, it is expected that this work has the potential to be considered as a part of a novel sono-thermo-chemotherapy.

\section{Acknowledgments}

This work was supported by the US National Science Foundation UPRM CREST Program (HRD-0833112 and HRD-1345156), the PR Institute for Functional Nanomaterials (EPS-100241), and the US National Institutes of Health (U54 CA 96300/u54 ca 96297). A special acknowledgement to Lantheus Medical Imaging
Inc. for donating most of Definity ${ }^{\circledR}$ ultrasound contrast agents used in this work (agreement MTA_2017001). The authors are grateful to Janet Méndez, Leonardo RodríguezNegrón, Christian Colón, Andreina Chiu-Lam, and Jorge

L. Castro-Torres for their contribution to this work.

\section{Disclosure}

The authors report no conflicts of interest in this work.

\section{References}

1. Minchinton AI, Tannock IF. Drug penetration in solid tumours. Nat Rev Cancer. 2006;6(8):583-592. doi:10.1038/nrc1893

2. Chatterjee DK, Diagaradjane P, Krishnan S. Nanoparticle-mediated hyperthermia in cancer therapy. Ther Deliv. 2011;2(8):1001-1014. doi: $10.4155 /$ tde. 11.72

3. Torres-Lugo M, Rinaldi C. Thermal potentiation of chemotherapy by magnetic nanoparticles. Nanomedicine (Lond). 2013;8(10):1689-1707. doi: $10.2217 / \mathrm{nnm} .13 .146$

4. Gobbo OL, Sjaastad K, Radomski MW, Volkov Y, Prina-Mello A. Magnetic nanoparticles in cancer theranostics. Theranostics. 2015;5 (11):1249-1263. doi:10.7150/thno.11544

5. Wilhelm S, Tavares AJ, Dai Q, et al. Analysis of nanoparticle delivery to tumours. Nat Rev Mater. 2016;1(5):16014. doi:10.1038/ natrevmats.2016.14

6. Alvarez-Berríos MP, Castillo A, Mendéz J, Soto O, Rinaldi C, TorresLugo M. Hyperthermic potentiation of cisplatin by magnetic nanoparticle heaters is correlated with an increase in cell membrane fluidity. Int J Nanomedicine. 2013;8:1003-1013. doi:10.2147/IJN.S38842

7. Alvarez-Berríos MP, Castillo A, Rinaldi C, Torres-Lugo M. Magnetic fluid hyperthermia enhances cytotoxicity of bortezomib in sensitive and resistant cancer cell lines. Int J Nanomedicine. 2014;9:145-153. doi:10.2147/IJN.S51435

8. Alamzadeh Z, Beik J, Pirhajati Mahabadi V, et al. Ultrastructural and optical characteristics of cancer cells treated by a nanotechnology based chemo-photothermal therapy method. J Photochem Photobiol B Biol. 2019;192:19-25. doi:10.1016/j.jphotobiol.2019.01.005

9. Yang $\mathrm{Y}$, Wang $\mathrm{F}$, Zheng $\mathrm{K}$, et al. Injectable PLGA/Fe3O4 implants carrying cisplatin for synergistic magnetic hyperthermal ablation of rabbit VX2 tumor. PLoS One. 2017;12(5):e0177049. doi:10.1371/journal.pone. 0177049

10. Qu Y, Li J, Ren J, Leng J, Lin C, Shi D. Enhanced synergism of thermo-chemotherapy by combining highly efficient magnetic hyperthermia with magnetothermally-facilitated drug release. Nanoscale. 2014;6(21):12408-12413. doi:10.1039/C4NR03384A

11. Court KA, Hatakeyama H, Wu SY, et al. HSP70 inhibition synergistically enhances the effects of magnetic fluid hyperthermia in ovarian cancer. $M o l$ Cancer Ther. 2017;16(5):966-976. doi:10.1158/1535-7163.MCT-160519

12. Lammertink BHA, Bos C, Deckers R, Storm G, Moonen CTW, Escoffre JM. Sonochemotherapy: from bench to bedside. Front Pharmacol. 2015;6(JUN). doi:10.3389/fphar.2015.00138

13. Yu H, Xu L. Cell experimental studies on sonoporation: state of the art and remaining problems. J Control Release. 2014;174(1):151-160. doi:10.1016/j.jconrel.2013.11.010

14. Paliwal S, Mitragotri S. Therapeutic opportunities in biological responses of ultrasound. Ultrasonics. 2008;48(4):271-278. doi:10.1016/j.ultras. 2008.02.002

15. Baghbani F, Moztarzadeh F. Bypassing multidrug resistant ovarian cancer using ultrasound responsive doxorubicin/curcumin co-deliver alginate nanodroplets. Colloids Surf B Biointerface. 2017;153:132-140. doi:10.1016/j.colsurfb.2017.01.051 
16. Sun J, Yin M, Zhu S, et al. Ultrasound-mediated destruction of oxygen and paclitaxel loaded lipid microbubbles for combination therapy in hypoxic ovarian cancer cells. Ultrason Sonochem. 2016;28:319-326. doi:10.1016/j.ultsonch.2015.08.009

17. Escoffre JM, Piron J, Novell A, Bouakaz A. Doxorubicin delivery into tumor cells with ultrasound and microbubbles. Mol Pharm. 2011;8(3):799-806. doi:10.1021/mp100397p

18. Sorace AG, Warram JM, Umphrey H, Hoyt K. Microbubblemediated ultrasonic techniques for improved chemotherapeutic delivery in cancer. J Drug Target. 2012;20(1):43-54. doi:10.3109/ 1061186X.2011.622397

19. Heath CH, Sorace A, Knowles J, Rosenthal E, Hoyt K. Microbubble therapy enhances anti-tumor properties of cisplatin and cetuximab in vitro and in vivo. Otolaryngol Neck Surg. 2012;146(6):938-945. doi:10.1177/0194599812436648

20. Chen P-Y, Liu H-L, Hua M-Y, et al. Novel magnetic/ultrasound focusing system enhances nanoparticle drug delivery for glioma treatment. Neuro Oncol. 2010;12(10):1050-1060. doi:10.1093/ neuonc/noq054

21. Wang Y-XJ, Leung KC-F, Cheung W-H, et al. Low-intensity pulsed ultrasound increases cellular uptake of superparamagnetic iron oxide nanomaterial: results from human osteosarcoma cell line U2OS. J Magn Reson Imaging. 2010;31(6):1508-1513. doi:10.1002/jmri.22173

22. Mo R, Yang J, Wu EX, Lin S. Instant magnetic labeling of tumor cells by ultrasound in vitro. J Magn Magn Mater. 2011;323 (17):2287-2294. doi:10.1016/j.jmmm.2011.04.008

23. Kolářová M, Poláková K, Tománková K, Havrdová M, Marková Z, Zbořil R. Rapid Cellular Uptake of Superparamagnetic Iron Oxide Nanoparticles by Using Low-Intensity Ultrasound. NanoCon 2013. Vol. 10, 2013.

24. Yang F, Li M, Cui H, et al. Altering the response of intracellular reactive oxygen to magnetic nanoparticles using ultrasound and microbubbles. Sci China Mater. 2015;58(6):467-480. doi:10.1007/ s40843-015-0059-9

25. Mérida F, Chiu-Lam A, Bohórquez AC, et al. Optimization of synthesis and peptization steps to obtain iron oxide nanoparticles with high energy dissipation rates. J Magn Magn Mater. 2015;394:361-371. doi:10.1016/j.jmmm.2015.06.076

26. Barrera C, Herrera AP, Bezares N, et al. Effect of poly(ethylene oxide)-silane graft molecular weight on the colloidal properties of iron oxide nanoparticles for biomedical applications. $J$ Colloid Interface Sci. 2012;377(1):40-50. doi:10.1016/j.jcis.2012.03.050

27. Barrera C, Herrera AP, Rinaldi C. Colloidal dispersions of monodisperse magnetite nanoparticles modified with poly(ethylene glycol). J Colloid Interface Sci. 2009;329(1):107-113. doi:10.1016/j.jcis.2008.09.071

28. Rodríguez Negrón L Physiological effects of focused ultrasound pulsation schemes on amphibian peripheral nerve structures. 2016.

29. Barrera C, Herrera A, Zayas Y, Rinaldi C. Surface modification of magnetite nanoparticles for biomedical applications. J Magn Magn Mater. 2009;321(10):1397-1399. doi:10.1016/j.jmmm.2009.02.046

30. Khandhar AP, Ferguson RM, Krishnan KM. Monodispersed magnetite nanoparticles optimized for magnetic fluid hyperthermia: implications in biological systems. J Appl Phys. 2011;109(7):07B310. doi:10.1063/1.3556948

31. Chem JM, Liu XL, Fan M, et al. Optimization of surface coating on $\mathrm{Fe} 3 \mathrm{O} 4$ nanoparticles for high performance magnetic hyperthermia agents. J Mater Chem. 2012;22:8235-8244. doi:10.1039/c2jm30472d

32. Yudina A, Lepetit-Coiffé M, Moonen CTW. Evaluation of the temporal window for drug delivery following ultrasound-mediated membrane permeability enhancement. Mol Imaging Biol. 2011;13 (2):239-249. doi:10.1007/s11307-010-0346-5

33. Hatakeyama H, Wu SY, Lyons YA, et al. Role of CTGF in sensitivity to hyperthermia in ovarian and uterine cancers. Cell Rep. 2016;17 (6):1621-1631. doi:10.1016/j.celrep.2016.10.020
34. Dalecki D. Mechanical bioeffects of ultrasound. Annu Rev Biomed Eng. 2004;6:229-248. doi:10.1146/annurev.bioeng.6.040803.140126

35. Fan P, Zhang Y, Guo X, et al. Cell-cycle-specific cellular responses to sonoporation. Theranostics. 2017;7(19):4894 4908. doi:10.7150/ thno. 20820

36. Knight KL, Draper DO. Therapeutic Modalities: The Art and Science. 2nd ed. Lippincott Williams \& Wilkins; 2013.

37. Feng Q, Liu Y, Huang J, Chen K, Huang J, Xiao K. Uptake, distribution, clearance, and toxicity of iron oxide nanoparticles with different sizes and coatings. Sci Rep. 2018;8(1):1-13. doi:10.1038/ s41598-018-19628-z

38. Lentacker I, De Cock I, Deckers R, De Smedt SC, Moonen CTW. Understanding ultrasound induced sonoporation: definitions and underlying mechanisms. Adv Drug Deliv Rev. 2014;72:49-64. doi:10.1016/j.addr.2013.11.008

39. Beik J, Shiran MB, Abed Z, et al. Gold nanoparticle-induced sonosensitization enhances the antitumor activity of ultrasound in colon tumor-bearing mice. Med Phys. 2018;45(9):4306-4314. doi:10.1002/ mp. 13100

40. Beik J, Abed Z, Shakeri-Zadeh A, Nourbakhsh M, Shiran MB. Evaluation of the sonosensitizing properties of nano-graphene oxide in comparison with iron oxide and gold nanoparticles. Phys E LowDimensional Syst Nanostructures. 2016;81:(January):308-314. doi:10.1016/j.physe.2016.03.023

41. Beik J, Abed Z, Ghadimi-Daresajini A, et al. Measurements of nanoparticle-enhanced heating from $1 \mathrm{MHz}$ ultrasound in solution and in mice bearing CT26 colon tumors. J Therm Biol. 2016;62:84-89. doi:10.1016/j.jtherbio.2016.10.007

42. Beik J, Khateri M, Khosravi Z, et al. Gold nanoparticles in combinatorial cancer therapy strategies. Coord Chem Rev. 2019;387:299-324. doi:10.1016/j.ccr.2019.02.025

43. $\mathrm{Hu} \mathrm{X}$, Kheirolomoom A, Mahakian LM, et al. Insonation of targeted microbubbles produces regions of reduced blood flow within tumor vasculature. Invest Radiol. 2012;47(7):398-405. doi:10.1097/ RLI.0b013e31824bd237

44. Lammertink B, Deckers R, Storm G, Moonen C, Bos C. Duration of ultrasound-mediated enhanced plasma membrane permeability. Int J Pharm. 2015;482(1-2):92-98. doi:10.1016/j.ijpharm.2014.12.013

45. Kosheleva OK, Lai T-C, Chen NG, Hsiao M, Chen C-H. Selective killing of cancer cells by nanoparticle-assisted ultrasound. J Nanobiotechnology. 2016;14(1):46. doi:10.1186/s12951-016-0194-9

46. Nomikou N, McHale AP. Exploiting ultrasound-mediated effects in delivering targeted, site-specific cancer therapy. Cancer Lett. 2010;296(2):133-143. doi:10.1016/j.canlet.2010.06.002

47. Rodríguez-Luccioni HL, Latorre-Esteves M, Méndez-Vega J, et al. Enhanced reduction in cell viability by hyperthermia induced by magnetic nanoparticles. Int $J$ Nanomedicine. 2011;6:373-380. doi:10.2147/IJN.S14613

48. Hildebrandt B, Wust P, Ahlers O. The cellular and molecular basis of hyperthermia. Crit Rev Oncol Hematol. 2002;43:33-56. doi:10.1016/ S1040-8428(01)00179-2

49. Chiu-Lam A, Rinaldi C. Nanoscale thermal phenomena in the vicinity of magnetic nanoparticles in alternating magnetic fields. Adv Funct Mater. 2016;26:3933-3941. doi:10.1002/adfm.20 1505256

50. Granato M, Lacconi V, Peddis M, et al. HSP70 inhibition by 2-phenylethynesulfonamide induces lysosomal cathepsin D release and immunogenic cell death in primary effusion lymphoma. Cell Death Dis. 2013;4(7):1-9. doi:10.1038/cddis.2013.263

51. Domenech M, Marrero-Berrios I, Torres-Lugo M, Rinaldi C. Lysosomal membrane permeabilization by targeted magnetic nanoparticles in alternating magnetic fields. ACS Nano. 2013;7 (6):5091-5101. doi:10.1021/nn4007048 


\section{Publish your work in this journal}

The International Journal of Nanomedicine is an international, peerreviewed journal focusing on the application of nanotechnology in diagnostics, therapeutics, and drug delivery systems throughout the biomedical field. This journal is indexed on PubMed Central, MedLine, CAS, SciSearch ${ }^{\mathbb{R}}$, Current Contents ${ }^{\mathbb{B}} /$ Clinical Medicine,
Journal Citation Reports/Science Edition, EMBase, Scopus and the Elsevier Bibliographic databases. The manuscript management system is completely online and includes a very quick and fair peer-review system, which is all easy to use. Visit http://www.dovepress.com/ testimonials.php to read real quotes from published authors.

Submit your manuscript here: https://www.dovepress.com/international-journal-of-nanomedicine-journal 